\title{
$O$ efeito de sugestões críticas na reelaboração de materiais didáticos de professores em formação inicial ${ }^{1}$
}

\author{
Philipe Pereira Borba de Araújo \\ Universidade Federal da Paraíba \\ prof.philipe.araujo@gmail.com \\ Marco Antônio Margarido Costa \\ Universidade Federal de Campina Grande \\ marcoantoniomcosta@gmail.com
}

\section{Resumo}

Este artigo tem por objetivo analisar o impacto das sugestões realizadas em um contexto de colaboração dialógico-crítica em sala de aula na reelaboração de materiais didáticos produzidos por professores em formação inicial. Este trabalho traz para discussão os resultados de uma pesquisa de intervenção realizada em uma disciplina da graduação em Letras/Inglês de uma universidade federal do Nordeste brasileiro. A análise, apoiada nos conceitos de mediação e de colaboração à luz da Teoria da Atividade Sócio-Histórico-Cultural, evidenciou marcas da colaboração nas sugestões, permitindo analisá-las como instrumento de mediação na perspectiva vygotskiana.

Palavras-chave: Colaboração. Formação de professores. Materiais didáticos.

\section{Abstract}

This article aims to analyze the impact of suggestions made in a dialogic-critical collaboration context in the classroom for the re-elaboration of didactic materials produced by pre-service teachers. This paper brings to discussion the results of an

${ }^{1}$ Este artigo é um recorte expandido de uma das seções de análise da dissertação de mestrado $O$ diálogo crítico colaborativo na formação de professores: ambivalências na representação da identidade docente na produção de materiais didáticos (ARAÚJO, 2018), produzida sob orientação do Prof. Dr. Marco Antônio Margarido Costa. A pesquisa completa encontra-se disponível em: https://bit.ly/36qjCW3. Acesso em: 23 maio 2020. 
O efeito de sugestões críticas...

intervention research carried out in an undergraduate degree in an English Bachelor of a federal university of the Northeast Region of Brazil. The analysis, supported by the concepts of mediation and collaboration under the light of the Activity Theory, showed marks of collaboration in the suggestions, allowing them to be analysed as a mediation tool in the Vygotskian perspective.

Keywords: Collaboration. Teacher training. Teaching materials.

\section{Introdução}

O papel do outro, fundamental na mediação de nossa relação com o mundo, é muitas vezes minorado ou ignorado em quase todas as instâncias da vida contemporânea. Essa perspectiva tem seus reflexos também na vida acadêmica: os sujeitos são muitas vezes tomados como seres autônomos, isolados dos contextos socio-históricos.

Acreditamos que a promoção do diálogo crítico-colaborativo nos contextos de formação de professores poderia contribuir para uma superação dessa perspectiva individualista dos sujeitos, das identidades, das consciências e dos conhecimentos. Acreditamos que, ao construir conhecimentos de forma dialógica, compartilhada, que se expande na relação com o outro, os professores em formação podem transformar suas identidades, suas atitudes e suas práticas pedagógicas.

Partindo desses pressupostos, este artigo tem por objetivo discutir como sugestões realizadas em um contexto de formação de professores de línguas pautado pelo diálogo contribuiu para a transformação dos materiais didáticos ${ }^{2}$ produzidos por professores em formação inicial.

Para atingir esse objetivo, primeiramente buscaremos entender os papéis desempenhados pelos interlocutores na Atividade "participar de um diálogo-crítico-colaborativo (DCC)", tendo o professor como mediador. Em seguida discutiremos de que forma a colaboração se expressa linguística e discursivamente nos DCC. Daremos enfoque à ação de sugerir

${ }^{2}$ É bom esclarecer que preferimos adotar o termo "material didático" e não outros, como "protótipo", "unidade" ou "atividade", por acreditarmos que a abrangência desse termo abarca de forma mais completa e ampla a diversidade de produções possíveis para os sujeitos da pesquisa. Consideramos a abrangência do termo "material didático" um convite mais aberto à criatividade e à multiplicidade de perspectivas. 
mudanças no material didático, destacando o papel dessas ações na transformação das perspectivas. Passaremos então a uma reflexão sobre como se ampliou (ou não) o espaço para a colaboração a partir da linguagem nas versões finais dos MD, após o momento de diálogo. Por fím, ressaltaremos como os sujeitos da pesquisa perceberam esses momentos como transformadores de suas próprias atitudes em sala de aula.

\section{Arcabouço teórico}

Este trabalho insere-se no quadro da Teoria da Atividade SocioHistórico-Cultural (TASHC). Essa teoria teve início a partir dos escritos de Vygotsky na década de 1920. Para Vygotsky, é por meio da mediação de artefatos que a cultura humana se produz e se modifica, isto é, sempre há um conjunto de artefatos que medeiam não só as relações e os processos transformadores entre o ser humano e a natureza, como também as relações dos seres humanos entre si.

Engeström (2001) explica que a inserção do conceito de artefato teve caráter revolucionário por permitir superar a separação entre 0 indivíduo cartesiano e a estrutura social. A partir disso, o sujeito não pode mais ser entendido sem seus meios culturais, e a sociedade não poderia ser entendida sem a agência de indivíduos que usam e produzem ferramentas. Como ressalta Engeström, "a orientação da ação para o objeto se tornou a chave para entender a psique humana"3 (ENGESTRÖM, 2001, p. 134).

Neste texto, trabalhamos com a linguagem partindo da premissa vygotskyana da centralidade do artefato e entendendo a linguagem como artefato mediador fundamental para a compreensão do humano. Assim, encaramos o estudo das atividades de linguagem - o diálogo crítico, neste trabalho - como um caminho para compreender a formação dos professores.

Nesse quadro, o conceito de mediação, segundo o próprio Vygotsky (1996 apud MOLON, 2015), configura-se como fato central de sua psicologia. Como explica Molon (2015), “a mediação não está entre dois termos que estabelecem uma relação. É a própria relação” (MOLON,

\footnotetext{
${ }^{3}$ No original: "The object-orientedness of action became the key to understanding human psyche".
} 
O efeito de sugestões críticas...

2015, p. 102). Esta acontece por meio dos signos, da palavra, dos instrumentos de mediação.

Nesse sentido, para Vygotsky, o sujeito constitui-se como um "agregado de relações sociais" (VYGOTSKY, 1986, p. 45 apud MOLON, 2015 , p. 115), tendo em vista que exige o reconhecimento do outro, em uma relação dialética, para se constituir como sujeito. A subjetividade é, portanto, socialmente construída, em um processo que vai se desenvolvendo com base em semelhanças e diferenças, aproximações e afastamentos em relação ao outro, sendo o sujeito "uma composição não harmônica dessas tensões e sínteses" (MOLON, 2015, p. 58). Nessa perspectiva, podemos conceituar o sujeito como "uma unidade múltipla, que se realiza na relação eu-outro, sendo constituído e constituinte do processo socio-histórico" (MOLON, 2015, p. 116).

Destaquemos que a concepção vygotskyana de sujeito não entende o indivíduo como resultado de um determinismo cultural (o sujeito como produto da cultura). Ao contrário, "parte do pressuposto de que as características de cada indivíduo vão sendo formadas a partir da constante interação com o meio [...]. Nesse processo, o indivíduo, ao mesmo tempo em que internaliza as formas culturais, as transforma e intervém em seu meio" (REGO, 2014, p. 94).

No contexto da TASHC, em uma perspectiva contrastante à tradicional (de que serviria para persuadir ou convencer), a argumentação estaria ligada à produção conjunta de objetos compartilhados, em um constante movimento coletivo em direção ao resultado da Atividade.

Nessa perspectiva, a argumentação, entendida como diálogo, passa a servir para o contraste de ideias e a construção de novos conhecimentos. Está ligada, portanto, à inovação e à criatividade, num processo de superação de significados historicamente cristalizados. Uma perspectiva de argumentação como diálogo propõe uma constante busca de novas ideias, a reavaliação constante dos pressupostos, o respeito a todos os participantes, o entrelaçamento dos discursos e o alargamento das perspectivas dos participantes por meio da reflexão crítica sobre os próprios pontos de vista.

A argumentação colaborativa torna-se crítica quando tem dois propósitos: a compreensão sobre como as relações de poder subjazem ao seu pensar e o redirecionamento do pensamento a interesses em longo prazo (NININ, 2013). O movimento na direção da argumentação crítica parte dos sujeitos da Atividade por meio da instauração e da manutenção de 
conflitos, da inserção de novos pontos de vista e do entrelaçamento das vozes.

Consideramos que a vivência de espaços abertos à argumentação no ensino superior, na formação inicial de docentes, é um passo importante para que essa disposição de promover o espaço para o diálogo aconteça na prática docente.

O conceito de colaboração está no cerne dos escritos de Vygotsky (1934). Para ele, é por intermédio da colaboração que nos tornamos quem somos, por estar ela no centro do processo de desenvolvimento. Em contextos educativos, Hashim e Jones (2007) apontam que:

A atividade colaborativa em grupo é a chave para promover a interação entre os estudantes na sala de aula. Através de um ambiente de aprendizado colaborativo, o aluno é encorajado a fazer perguntas, explicar e justificar opiniões, articular o raciocínio, elaborar e refletir sobre o conhecimento recebido ${ }^{4}$ (HASHIM; JONES, 2007, p. 15).

Magalhães (2014), apoiada em John-Steiner (2000), acrescenta ainda que colaborar envolve "um movimento dialético entre vozes sociais, socio-históricas e culturalmente constituídas que [...] são responsáveis pela criação de contextos de 'intensidade emocional' e de uma 'zona de ação desconfortável'” (MAGALHÃES, 2014, p. 25). Nos contextos de colaboração, os seres humanos "se constituem e se transformam constantemente e, do mesmo modo, criam e transformam seus contextos de ação" (MAGALHÃES, 2014, p. 25). Entende-se assim a colaboração como um processo de compreensão e transformação de si mesmo, do outro e do mundo.

Na mesma linha, Ninin (2013) entende a colaboração como um "processo interacional de criação compartilhada, mediado pela linguagem, que nasce de uma prática social de indivíduos em busca da reconstrução e reorganização de saberes em um dado contexto" (NININ, 2013, p. 64).

\footnotetext{
${ }^{4}$ No original: "Collaborative group activity is the key to promote student interaction in the classroom. Through a collaborative learning environment the student is encourage asking questions (sic), explaining and justifying opinions, articulating reasoning, and elaborates and reflects upon the received knowledge".
} 
O efeito de sugestões críticas...

Magalhães (2014) corrobora a perspectiva de Ninin (2013) ao apontar como elementos fundantes da colaboração o senso de compromisso, a responsabilidade, a mutualidade e a interdependência produtiva, a confiança e o respeito entre os participantes, o compartilhamento de outras maneiras de pensar e a abertura para a possibilidade de fala.

Percebemos, assim, que a colaboração se configura como uma atividade de linguagem que parte do engajamento mútuo, da diferença para a criação de uma "zona de ação desconfortável" (MAGALHÃES, 2014, p. 25), que leva a um movimento dialético transformador das identidades e do agir humano. Em outras palavras, poderíamos dizer que por meio da colaboração se potencializam espaços para a criação de ZDP.

Entende-se, assim, que a colaboração crítica, exercida por meio da linguagem, sob a perspectiva de argumentar para compreender o ponto de vista do outro (LIBERALI, 2012), possibilita a construção de uma atmosfera favorável ao desenvolvimento humano, à compreensão e à transformação de si mesmo, do outro e do mundo (MAGALHÃES, 2014).

Ao se destacar o conflito e a colaboração como focais para o desenvolvimento do pensamento crítico, faz-se pertinente considerar com maior ênfase o ato de perguntar, pois é principalmente nesse ato que se instaura a atividade argumentativa, visto que este pode permitir abertura de espaço para exposição do contraditório, para o pensar crítico, além de convidar à participação (NININ, 2013).

No viés da TASHC, as perguntas são entendidas como ferramentas ou artefatos culturais mobilizadores, que impulsionam os sujeitos em direção ao objeto compartilhado. Em outras palavras, compreendemos que as perguntas têm o potencial de desempenhar o papel fundamental de promover a transformação do objeto em resultado por seu caráter dialógico expansivo.

Perguntas que permitem uma expansão dialógica são aquelas que ampliam o espaço dialógico, permitindo a entrada de posições alternativas. De modo geral, perguntas expansivas minimizam a responsabilidade autoral por indicarem uma postura não definitiva de quem pergunta. Os significados são mantidos em aberto por meio de modalizações, e esse movimento mobiliza a participação e uma postura ativa por parte do outro, num movimento de construção progressiva de sentimento de segurança, confiança e responsividade. 
Perguntas dialogicamente contrativas, ${ }^{5}$ em contrapartida, restringem a diversidade de vozes e funcionam como um bloqueio para a entrada de novas vozes. Perguntas cujo propósito é avaliar o saber do outro serão, por conseguinte, contrativas, tendendo ao monológico. Uma pergunta contrativa pode apresentar um caráter de ordem e, desse modo, pode mobilizar a participação apenas daquele que se sente seguro em responder o que se espera como resposta correta, ou seja, uma pseudoparticipação.

A partir das reflexões sobre perguntas, o que se espera é que o ato de perguntar oportunize abertura para que o outro manifeste seu pensamento e compartilhe suas experiências. Espera-se ainda que as perguntas gerem conflitos, ${ }^{6}$ que, por sua vez, desencadeiem a aprendizagem por meio da reflexão.

De forma sucinta, podemos delinear algumas características da argumentação entendida como diálogo: (1) é desenvolvida com base na colaboração entre todos os envolvidos; (2) pressupõe que é a partir do compartilhamento de ideias que se chega a possíveis soluções coletivas; (3) tem natureza criativa; (4) valoriza abertura à transformação das perspectivas com base na reflexão sobre os posicionamentos de cada um.

Por conseguinte, percebemos que o pensar com o outro é parte imprescindível do desenvolvimento cognitivo e motor da criatividade. A universidade e a escola, a partir de uma abertura para o DCC, têm potencial para se tornarem loci de busca permanente por soluções coletivas e criativas para os problemas que nos afligem e para a superação do individualismo crescente na sociedade de hoje.

\footnotetext{
${ }^{5}$ Para os propósitos desta pesquisa, mobilizamos apenas a distinção entre perguntas dialogicamente expansivas e contrativas. Para uma categorização mais aprofundada das perguntas, no viés da TASHC, sugerimos consultar Ninin (2013).

${ }^{6}$ Esclarecemos que a noção de conflito, nessa visão, não diz respeito a uma postura de enfrentamento ou desentendimento, como aparece no senso comum. Pelo contrário, diz respeito a uma postura de contestação recíproca dos fundamentos que sustentam os argumentos com vistas à superação conjunta dos pontos de vista anteriores dos envolvidos.
} 
O efeito de sugestões críticas...

\section{Procedimentos metodológicos}

Situamos esta pesquisa no paradigma de pesquisa crítica de colaboração. Como descrito por Magalhães (2010), esse método de investigação em Linguística Aplicada tem caráter intervencionista e pautase na colaboração dos participantes, permitindo a todos a negociação de papéis na construção de conhecimento e a reflexão em suas ações diárias. Ou seja, pretende atingir transformação na realidade social ao permitir aos participantes que encarem o mundo sob uma ótica diferente.

Trata-se de uma pesquisa de natureza aplicada e de cunho explicativo, por se voltar a um problema específico, de natureza local, e por buscar identificar os fatores que contribuem para a ocorrência de fenômenos (GIL, 2007). No nosso caso, a pesquisa foi realizada em uma universidade pública e volta-se à transformação da esfera local, mais especificamente no contexto de formação de professores de língua inglesa.

Os sujeitos desta pesquisa são cinco professores em formação inicial matriculados no quinto período do curso de Letras-Inglês de uma instituição federal de ensino superior, todos com idades entre 18 e 21 anos. $^{7}$

Os dados foram gerados em 26 encontros da disciplina Teoria e Práticas de Leitura. Um dos produtos da disciplina foi a criação de materiais didáticos a serem utilizados para a prática docente dos sujeitos. Logo na primeira semana foi produzida uma primeira versão de cada material individualmente, e esse material foi retrabalhado e modificado a partir das reflexões em grupo, das sugestões dos colegas e das leituras realizadas ao longo da disciplina.

Dividimos as ações em sala de aula na disciplina Teorias e Prática de Leitura em três movimentos, que se repetem e se intercalam ao longo de todo o curso: (1) produção/modificação dos materiais didáticos; (2) leituras e diálogo com base nas teorias estudadas; (3) análise crítica das produções (chamadas aqui de Diálogos Crítico-Colaborativos).

Cada encontro teve duração aproximada de duas horas, e dois desses encontros foram registrados em áudio com a autorização dos participantes. Após os encontros, trechos do DCC foram transcritos e utilizados para a Análise.

${ }^{7}$ Com o intuito de preservar as identidades, usamos a letra "A" seguida de um número para cada um dos sujeitos da pesquisa (A1, A2, A3, A4 e A5). 
Os DCC, em que de fato ocorreram análises coletivas dos materiais produzidos pelos próprios professores em formação, ocorreram no $20^{\circ}$ encontro e no $25^{\circ}$. Nesses encontros, o professor-pesquisador (PP) entregou um dos materiais didáticos a cada um dos sujeitos, de modo que cada um ficou responsável pela análise do material de um dos colegas. Após alguns minutos para leitura desses materiais, houve o compartilhamento de impressões, pontos em comum e sugestões de mudança em relação a essas produções tanto no que se refere aos textos escolhidos como em relação à forma como a compreensão desses textos foi proposta nesse material. Destacamos que em nenhum momento o PP adotou uma postura de demandar "correções" nesses materiais, seja em relação a questões linguísticas, seja em relação a questões metodológicas. Todas as sugestões de mudanças nos MD, em todos os âmbitos, partiram das considerações coletivas nos DCC.

\section{Análise}

Analisaremos aqui as sugestões com mais ênfase do que outros momentos do diálogo. A ação de sugerir funcionou como espaço aberto a conflitos com potencial de transformação ou recriação coletiva e criativa dos conceitos que embasaram as ações de produção de material didático. Ou seja, entendemos as sugestões como o momento particular em que a negociação de sentidos poderia culminar na transformação das perspectivas. As sugestões de mudança, apesar de à primeira vista parecerem se voltar aos materiais produzidos, na verdade contribuíram para uma reelaboração de conceitos mentais, influindo, talvez, em ações futuras. Daí nosso interesse especificamente nessas ações.

Em razão de nossas observações, propomos que essas sugestões sejam classificadas em relação a quatro fatores: (a) quanto aos elementos a serem mudados; (b) quanto aos tipos de mudança; (c) quanto às motivações; e (d) quanto às implicações. Descrevemos cada uma delas a seguir.

a) Quanto aos elementos a serem mudados, classificamos as sugestões em três grupos: (1) sugestões em relação a elementos dos textos trabalhados no MD; (2) sugestões em relação ao 
O efeito de sugestões críticas...

tipo/teor das perguntas; e (3) sugestões em relação a outros elementos que compõem o MD (imagens, layout, anexos, formatação, dentre outros).

b) Classificamos os tipos de mudança em quatro grupos: (1) de acréscimo, quando há adição de elementos; (2) de supressão, quando se propõe a eliminação de elementos; (3) de relocação, quando há a troca de ordem entre os elementos; e (4) de substituição, quando há a supressão de um elemento aliada à adição de outro no mesmo ponto.

c) Em relação às motivações, temos sugestões motivadas (1) pelos momentos de diálogo crítico-colaborativo; (2) por leituras teóricas; (3) por reflexões em outras aulas; e (4) por comentários dos colegas em outros momentos. Lembramos que as motivações das sugestões nem sempre ficarão transparentes à análise, e que mais de uma motivação pode ocorrer na mesma sugestão.

d) Por fim, quanto às implicações, temos apenas dois grupos: (1) sugestões que implicaram mudanças no MD a que se dirigiram; e (2) sugestões que não implicaram mudanças no MD a que se dirigiram.

Tendo em vista essa classificação, elencamos todas as sugestões que encontramos nos dois DCC no Quadro 1. Discutiremos esse quadro nos parágrafos seguintes. 
Quadro 1. Quadro-resumo das sugestões de mudança nos $\mathrm{MD}^{8}$

Philipe Araújo; Marco Antônio Costa

\begin{tabular}{|l|l|l|l|l|l|}
\hline DCC & $\#$ & SUJEITOS & SUGESTÃo & TIPOLOGIA & $\begin{array}{l}\text { Mudança } \\
\text { no MD? }\end{array}$ \\
\hline & 1 & A3 $\rightarrow$ A1 & $\begin{array}{l}\text { Dar opções ou exemplos que ajudem os alunos } \\
\text { nas perguntas metacognitivas. }\end{array}$ & Substituição de pergunta. & Sim. \\
\cline { 2 - 6 } & 2 & PP $\rightarrow$ A2 & $\begin{array}{l}\text { Inserir título dentro da moldura que enquadra o } \\
\text { texto. }\end{array}$ & Substituição de layout. & Sim. \\
\cline { 2 - 6 } & 3 & A1 $\rightarrow$ A4 & $\begin{array}{l}\text { Adicionar pergunta antes do texto para mobilizar } \\
\text { saberes dos alunos. }\end{array}$ & Acréscimo de pergunta. & Sim. \\
\cline { 2 - 6 } & 4 & A5 $\rightarrow$ A3 & $\begin{array}{l}\text { Adicionar pergunta sobre as pistas textuais que } \\
\text { permitem o reconhecimento do gênero de cada } \\
\text { um dos gêneros trabalhados. }\end{array}$ & Acréscimo de pergunta. & Sim. \\
\cline { 2 - 6 } & 5 & A3 $\rightarrow$ A1 & $\begin{array}{l}\text { Adicionar perguntas para os alunos retomarem o } \\
\text { que viram no texto. }\end{array}$ & Acréscimo de pergunta. & Não. \\
\hline & 6 & PP $\rightarrow$ todos & $\begin{array}{l}\text { Adicionar perguntas pensando na função social do } \\
\text { texto. }\end{array}$ & Acréscimo de pergunta. & Não. \\
\hline & 7 & A1 $\rightarrow$ A4 & $\begin{array}{l}\text { Substituir o texto por outro que abranja mais a } \\
\text { realidade local. }\end{array}$ & Substituição de texto. & Sim. \\
\hline
\end{tabular}

${ }^{8}$ Classificadas quanto ao momento em que são realizadas, quanto ao autor da proposta, quanto à tipologia (tipo de mudança e elemento a ser mudado) e quanto às implicações

9 *Inserimos o autor da sugestão e o autor do MD, nessa ordem, separados por uma seta. Portanto, leia-se "A3 $\rightarrow$ A1" como "sugestão de A3 para o MD de A1". 
O efeito de sugestões críticas...

\begin{tabular}{|l|l|l|l|l|l|}
\hline \multirow{2}{*}{} & 8 & A2 $\rightarrow$ A5 & $\begin{array}{l}\text { Mudar a ordem das perguntas que aparecem após } \\
\text { o texto. }\end{array}$ & Relocação de perguntas. & Sim. \\
\cline { 2 - 6 } & 9 & A2 $\rightarrow$ A5 & $\begin{array}{l}\text { Trocar pergunta do tipo fechada por uma pergunta } \\
\text { aberta. }\end{array}$ & Substituição de pergunta. & Não. \\
\cline { 2 - 6 } & 10 & PP $\rightarrow$ A4 & Apresentar o texto no seu layout original da web. & $\begin{array}{l}\text { Acréscimo de elementos } \\
\text { multimodais nos textos. }\end{array}$ & Não. \\
\cline { 2 - 7 } & 11 & A2 $\rightarrow$ A2 & Inserir questões para discussões em grupo. & Acréscimo de perguntas. & Não. \\
\cline { 2 - 7 } & 12 & A3 $\rightarrow$ A3 & $\begin{array}{l}\text { Substituir um dos textos escolhidos por um texto } \\
\text { mais multimodal. }\end{array}$ & Substituição de texto. \\
\hline
\end{tabular}

Fonte: produzido pelos autores 
O Quadro 1 mostra-nos que houve sete sugestões (numeradas cronologicamente de 1 a 7) no DCC do primeiro dia e cinco sugestões (numeradas cronologicamente de 8 a 12) no DCC do segundo. A maior parte das sugestões partiu dos alunos; apenas três delas partiram do PP. É interessante notar que as sugestões 11 e 12 partiram, respectivamente, dos sujeitos A2 e A3 e se voltaram para eles mesmos, em um processo reflexivo verbalizado/compartilhado durante o diálogo.

Quanto ao tipo de mudança, podemos perceber que a maior parte das sugestões foi de acréscimo (seis no total) e de substituição (cinco no total). Apenas uma sugestão foi de relocação. Poderíamos interpretar a ausência de sugestões de supressão como mais uma marca de colaboração: sempre que percebiam elementos que, segundo eles, deveriam ser retirados do $\mathrm{MD}$, os sujeitos tinham o cuidado de propor elementos que os substituíssem, possivelmente como forma de evitar um esvaziamento dos MD dos colegas.

Quanto aos elementos a serem mudados, a maior parte das sugestões referia-se às perguntas presentes nos MD (oito no total). Poucas se referiam aos textos abordados ou a outros elementos que compõem os MD (quatro no total). Essa preocupação maior com as perguntas do que com a escolha dos textos em ambos os diálogos poderia ser explicada por uma maior preocupação por parte do PP em propor que a reflexão fosse mais dirigida à forma de trabalhar os textos escolhidos pelos alunos e menos à escolha dos textos. As implicações da ausência de reflexões mais profundas acerca da escolha dos textos serão discutidas na segunda seção de análise.

No Quadro 1, observamos também que apenas metade das sugestões implicou transformações nos MD. É curioso perceber que nenhuma das poucas sugestões feitas pelo PP implicou mudanças. Isso sugere que os alunos tendem a aceitar mais facilmente as sugestões feitas pelos colegas do que aquelas feitas pelo PP.

Em relação à motivação das mudanças nos $\mathrm{MD}$, temos um exemplo no excerto 11 de mudança motivada pelas leituras feitas na disciplina Teorias e Prática de Leitura. Nesse momento do DCC, o PP pergunta a A5 se as leituras acerca da Teoria dos Multiletramentos contribuíram para a escolha do gênero infográfico em seu MD.

Excerto 1: trecho do primeiro DCC. 
O efeito de sugestões críticas...

PP: Queria até perguntar a A5: teve influência da teoria que a gente tava lendo? Foi pelas leituras de Multiletramentos que se fez?

A5: Sim, porque eu não tinha colocado... Eu pensei em colocar um infográfico, porque é multimodal, mas eu não pedi pra eles observarem as imagens. Aí eu acrescentei essa pergunta (DCC, excerto 2.4).

No excerto 1 percebemos que as leituras e as discussões sobre o conceito de multimodalidade contribuíram para a produção do MD, como também influenciaram na escolha das perguntas. (Na fala de A5: "Eu pedi pra eles observarem as imagens. Aí eu acrescentei essa pergunta”).

Nas páginas seguintes destacaremos dois momentos dos DCC em que percebemos impactos das sugestões na configuração dos MD.

Podemos observar na Figura 1 uma minibiografia de Edgar Allan Poe obtida na Wikipédia e apresentada por A2 na primeira versão de seu MD como atividade introdutória (warm-up) para o texto central do MD: um conto de terror de Poe. Como se vê na Figura 1, o texto é apresentado separado das perguntas de compreensão que o seguem por uma borda que circunda todo o texto.

Durante o primeiro e o segundo diálogos, A4 ficou responsável pela análise do MD de A2. Em um determinado momento, quando provocada pelo PP a comentar sobre as perguntas que encontrou no MD do colega, A4 acaba por desencadear, sem querer, um conflito que culminou em uma mudança no MD de A2. Analisemos o excerto 2. 
Figura 1. Minibiografia de Edgar Allan Poe apresentada na primeira versão do MD de A2

\begin{abstract}
WARM-UP
Who was Edgar Allan Poe?

Edgar Allan Poe was born on January 19, 1809. His parents were two touring vaudeville actors, David Poe Jr. and Elizabeth Arnold Hopkins. David left the family under unknown circumstances whilst Poe was an infant. When Poe was two, his mother died of tuberculosis, leaving him an orphan. The wealthy John Allan took Edgar into his 1815, the Allan family went to an English private family moved back to After moving back to University of Virginia in gambled, lost money, and became angry, and cut off all published his first work, a home in Richmond, Virginia. In moved to England. Young Poe school. After five years, the Richmond, Virginia.

Virginia, Poe entered the 1826. While there, he went into debt. John Allan contact with Poe. In 1827, Poe and Other Poems. Poe did not have his name published in the book; it was attributed to "a Bostonian."
\end{abstract}

From https://simple.wikipedia.org/wiki/Edgar_Allan_Poe

1. Have you ever read some of his short stories or poems?

2. If yes, which is/are your favorite one/s?

\title{
Fonte: MD do aluno
}

Excerto 2: trecho do DCC do dia 27/07.

A4: Em cima tem uma pergunta, eu acho, da biografia.

PP: Ah, tem uma pergunta também?

A4: "Who was Edgar Allan Poe?"

A2: É o título do texto.

A4 e PP: Ah!

A4: É porque tá em cima.

PP: Olha que interessante! Tem a ver com design do texto. É porque o texto está dentro de um:: quadradinho, mas o título ficou fora. É interessante. Pode ser uma coisa para se modificar também, né?, quando for fazer outra versão, de colocar dentro do quadradinho. Acho que fica mais claro pro aluno. Eu também, eu 
O efeito de sugestões críticas...

acho que eu pensei também que era uma pergunta pra fazer antes e você depois ler o texto, que não teria título. Mas, realmente, ele tá centralizado, o que leva a gente a pensar "talvez seja o título".

O trecho do diálogo do excerto 2 inicia-se com um destaque de A4 a respeito do texto de $\mathrm{A} 2$. O PP, que já analisara os MD de todos antecipadamente, talvez tenha notado o mal-entendido de A4 e seu potencial para a criação de um espaço de conflito. A pergunta do PP, nesse contexto, além de espelhar a fala de A4, funciona como pedido de explicação. Então, A4 sustenta seu ponto de vista com a leitura da pergunta. Nesse momento, A2 esclarece que, na verdade, aquilo que A4 identificara como mais uma pergunta de compreensão se tratava do título do texto. A4 e o PP demonstram, então, surpresa com uma interjeição, e A4 atribui o mal-entendido à forma como o texto foi apresentado: "É porque [o título] tá em cima".

É evidente, dado o contexto em análise, que a constatação de A4 não é apenas em relação ao fato de o título estar acima do texto (o que seria uma obviedade, visto que este é o lugar em que esperamos encontrar o título na maioria dos gêneros), mas em relação ao fato de o título estar fora da borda que circunda o corpo do texto. O PP aproveita então esse momento para realizar quatro ações:

1) destaca para todos o motivo do mal-entendido e sua relação com um aspecto multimodal do texto, ajudando a explicar o mal-entendido de A4 em sua interface com a teoria estudada ("Olha que interessante! Tem a ver com design do texto. É porque o texto está dentro de um:: quadradinho, mas o título ficou fora. É interessante.’);

2) propõe uma mudança, de forma modalizada, e apresenta como suporte uma possível clareza maior para o leitor ("Pode ser uma coisa para se modificar também, né?, quando for fazer outra versão, de colocar dentro do quadradinho. Acho que fica mais claro pro aluno.”);

3) apresenta sua hipótese inicial a respeito do título também como suporte à sua sugestão de mudança ("Eu também, eu acho que eu pensei também que era uma pergunta pra fazer antes e você depois ler o texto, que não teria título"); e

4) para modalizar o discurso, destaca um suporte que sustenta a posição de A2 ("Mas, realmente, ele tá centralizado, o que leva a gente a pensar "talvez seja o título"'). 
Podemos notar, observando a Figura 2, que o conflito gerado pelo mal-entendido de A4 culminou em uma mudança na disposição do título na versão do material de A2.

Figura 2. Minibiografia de Edgar Allan Poe apresentada na segunda versão do MD de A2

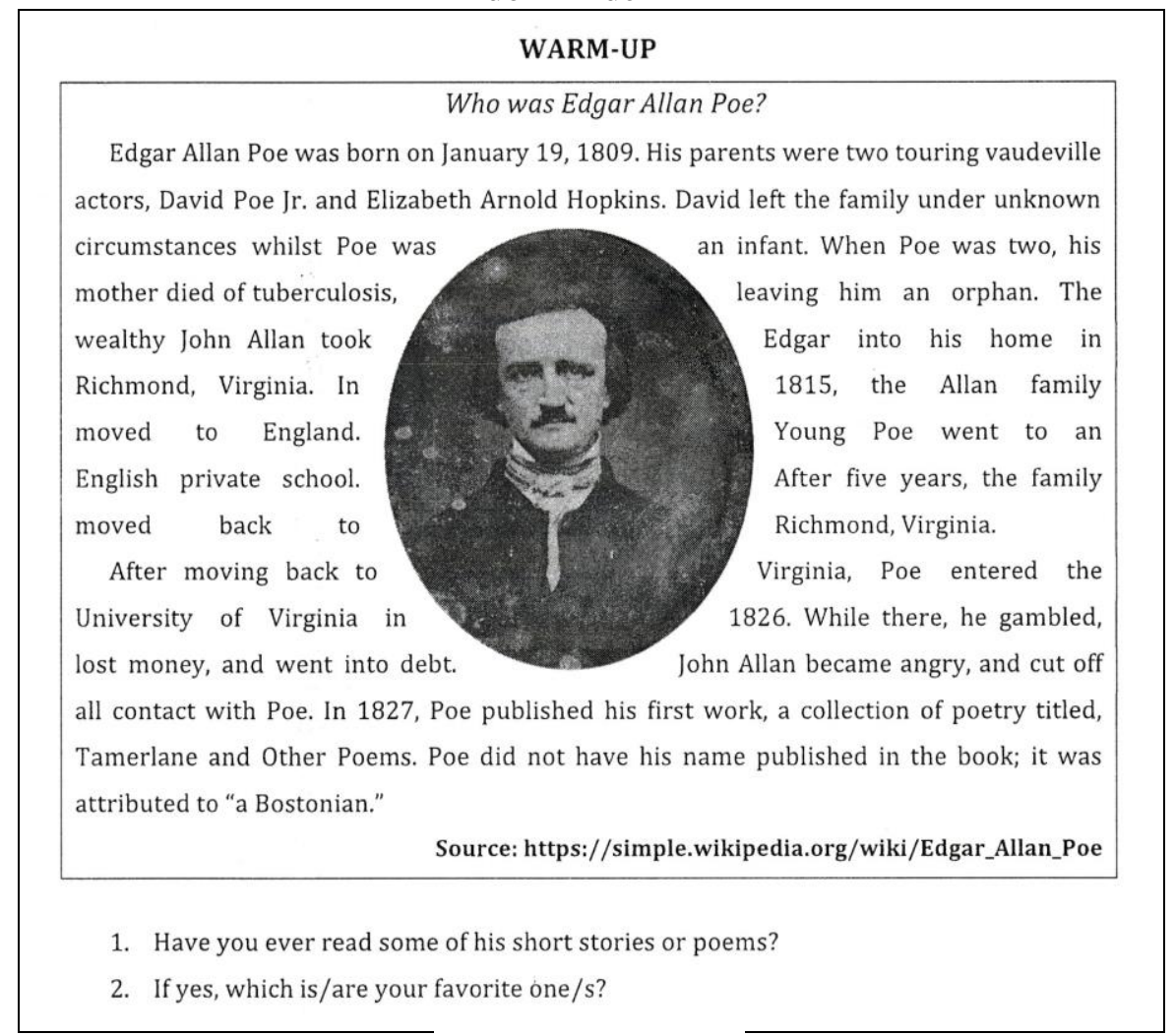

\section{Fonte: MD do aluno}

Curiosamente, A4 também pesquisou um verbete na Wikipédia para criar seu MD. Em sua primeira versão do MD, trouxe um trecho do verbete sobre o Rock in Rio e o relato apreciativo de uma pessoa que frequentou o evento, também obtido na web. Vemos na Figura 3 o layout 
O efeito de sugestões críticas...

apresentado por A4. Podemos notar que os elementos multimodais do texto foram eliminados, sendo apenas a parte linguística extraída do texto.

No trecho do diálogo que destacamos no excerto 3 temos o momento em que A1 propõe a A4 uma alteração na escolha dos textos.

Excerto 3: trecho do primeiro DCC.

A1: Nessa unidade aqui eu mudaria, por exemplo, é::: como tá falando sobre um evento, poderia ser um evento que... que:: abrangesse mais a realidade, o contexto das pessoas, é:::, que estão fazendo a atividade. Como, por exemplo, se fosse algo daqui de Campina Grande, poderia ser sobre o Parque do Povo, ou algo desse tipo, já que tem essa questão aqui: "Baseado nos dois textos, desenvolva uma crítica positiva ou negativa sobre o Rock in Rio". Eu acho que poderia ajudar se o contexto fosse mais alcançável.

PP: Hmmm. De trazer mais pra a realidade do aluno... É, poderia, por exemplo, relacionar com... com o Parque do Povo. Pensar assim: "tem a ver?", "o que você acha de parecido?", "o que você acha de diferente?". 


\section{Figura 3. Verbete sobre o Rock in Rio e relato opinativo sobre o evento ${ }^{10}$}

01. Read the texts:

First text:

Rock in Rio is a recurring music festival originating in Rio de Janeiro, Brazil. It later branched into other locations such as Lisbon, Madrid and Las Vegas. Six incarnations of the festival were held in Rio de Janeiro, in 1985, 1991, 2001, 2011, 2013 and 2015, seven in Lisbon, in 2004, 2006, 2008, 2010, 2012, 2014 and 2016, three in Madrid in 2008, 2010 and 2012, and one in Las Vegas, in 2015. The seventh Brazilian edition will happen from September 15 to 24, 2017. Brazilian entrepreneur and advertiser Roberto Medina was responsible for the inception and organization of the festival, as well as moving the 2004 edition to Lisbon, while controversially keeping the brand "Rock in Rio".

In 2011, Rock in Rio returned to its original location, Rio de Janeiro, with a new line-up of singers and groups. Rock in Rio is one of the largest music festivals in the world, with 1.5 million people attending the first event, 700,000 attending the second and fourth, about 1.2 million attending the third, and about 350,000 people attending each of the three Lisbon events. The first edition of the festival was held from January 11-20, 1985. Queen, George Benson, Rod Stewart, $A C / D C$ and Yes were the headliners, each occupying top spot for two nights (Benson, however, ceded it to James Taylor for their second night in the same bill, due to the huge delay Taylor's extended performance had caused to his concert two days before). About 1.4 million people attended the 10-day-long festival.

https://en.wikipedia.org/wiki/Rock in Rio

Second text:

In 2011 I was quite hooked to see the Guns, so not like virtually nothing of the festival itself, just the shows of the world stage. However, this year, a little more "experienced" in festivals, decided to meet the entire city of rock and little bothered to stand near the stage, which I believe to be a waste of time, sweat and patience, and that's the point I'm getting at. Of course, I don't have the patience to hear Rihanna, Katy Perry and their derivatives, however I NEVER turn down an invitation to attend the Rock in Rio, even on the nights more pops, you know why? Rock in Rio is much more than the shows of the world stage, Rock in Rio is a sum of party, friends, music, shows, attractions of the most varied, structure, giving sponsors a show on their guerrillas and actions, amusement park and more, and all this combined generates an unforgettable energy and inexplicable, who was already can understand.

\section{https://whiplash.net/materias/opinioes/231458-rockinrio.html}

\section{Fonte: MD da aluna}

A sugestão de A1 culminou em uma transformação no MD de A4. A partir da ideia apresentada por A1, A4 decidiu incluir no seu MD um

${ }^{10}$ Ambos apresentados na primeira versão do material didático de A4. 
contraste entre o Rock in Rio e o São João de Campina Grande (ver Figura 4). O material passa a se aproximar, assim, da "realidade do aluno".

Figura 4. Verbete sobre o Rock in Rio e texto informativo sobre o São João apresentados na segunda versão do MD de A4.

* Read the texts:

First text:

Rock in Rio is a recurring music festival originating in Rio de Janeiro, Brazil. It later branched into other locations such as Lisbon, Madrid and Las Vegas. Brazilian entrepreneur and advertiser Roberto Medina was responsible for the inception and organization of the festival, as well as moving the 2004 edition to Lisbon, while controversially keeping the brand "Rock in Rio".

In 2011, Rock in Rio returned to its original location, Rio de Janeiro, with a new line-up of singers and groups. Rock in Rio is one of the largest music festivals in the world. The first edition of the festival was held from January 11-20, 1985. Queen, George Benson, Rod

Stewart, AC/DC and Yes were the headliners, each occupying top spot for two nights (Benson, however, ceded it to James Taylor for their second night in the same bill, due to the huge delay Taylor's extended performance had caused to his concert two days before). About 1.4 million people attended the 10-day-long festival.

\section{https://en.wikipedia.org/wiki/Rock in Rio}

Second text:

Caruaru is a small city of about 300,000 people, in Pernambuco State. Campina Grande has a population of 385,000 people and is in Paraiba State. During the month of June these two cities go through a great transformation. The government and the residents organize themselves to make Festa Junina into a massive tourist attraction. In 2009 each city was visited by about 2 million tourists, as well as journalists from all over Brazil who went to cover the events. In the Northeast it is common for a Festa Junina to be called "Saint John". Campina Grande says it organizes "the world's biggest Saint John." But Caruaru says the same thing. Each city holds dozens of events in a period of at least 30 days, including shows played by leading names in Brazilian popular music. Throughout this period, the parties drive the local economy

\section{Fonte: MD da aluna}

Em um trecho da entrevista coletiva realizada dois meses após a experiência de produção dos MD, o PP pergunta aos professores em formação se a experiência foi significativa. Destacamos a resposta de A4 no excerto 4. 
Excerto 4: trecho da entrevista coletiva realizada após o fim da disciplina.

A4: Eu gostei. Somente quando A1 falou e comentou a minha [atividade], eu gostei bastante, porque eu não tinha pensado nisso. Eu acho que é legal compartilhar.

Esse recorte da fala de A4 permite-nos perceber que, para ela, a experiência foi significativa porque o olhar de A1 para o material que A4 produzira permitiu uma expansão das possibilidades de abordar novos temas sobre os quais não havia pensado.

Destacamos até aqui os papéis dos alunos na criação de espaços colaborativos, por meio da linguagem, nos momentos de diálogo. É importante destacar, no entanto, a valoração dos sujeitos da pesquisa acerca da realização dos diálogos em sala de aula para que compreendamos como os alunos se posicionaram a respeito dessa experiência.

Coletamos as percepções dos alunos acerca dos diálogos por meio de avaliações sobre a forma como a disciplina estava sendo conduzida. Em dois momentos, aproximadamente à metade e ao final da disciplina, cada aluno recebeu uma folha de papel na qual pedimos que destacassem os pontos positivos e os pontos negativos em relação ao andamento da disciplina (pedimos que levassem em conta metodologia, avaliação, conteúdos trabalhados etc.). Para garantir que os alunos se sentissem mais à vontade para avaliar, pedimos que não informassem seus nomes nas folhas que receberam. Notamos que quatro dos cinco sujeitos destacaram, dentre os pontos positivos, elementos que têm relação com a abertura ao diálogo em sala de aula. Destacamos alguns desses pontos a seguir.

Excerto 5: trechos dos feedbacks em relação à disciplina Teorias e Prática de Leitura coletados em aula.

a) "Discussão em grupos: Torna a participação na aula mais acessível a alunos reticentes, sendo uma participação colaborativa".

b) [O professor] "escuta todas as opiniões apresentadas".

c) [O professor] "Aceita os pontos de vista".

d) [O professor] "considera as ideias dos alunos como algo que gera discussão ou como acréscimo a aula [sic], nunca demonstrando que o aluno cometeu um erro ao dar determinada opinião". 
Percebemos no feedback dado pelos alunos que a disposição por parte do PP em ouvir e considerar o ponto de vista dos alunos foi sempre destacada como ponto positivo. Podemos afirmar, com base nos dados anteriores, que, de forma geral, os alunos perceberam o diálogo tanto como um fator que contribuiu para uma mudança de sua postura em sala de aula como algo que despertou um maior interesse por parte da turma.

Os pontos que destacamos nos DCC e nas percepções dos sujeitos da pesquisa até aqui nos permitem afirmar que houve colaboração em ambos os diálogos, e que essa colaboração foi percebida como positiva para a formação desses professores. Percebemos que houve engajamento de todos os participantes da Atividade no sentido de produzir um Objeto compartilhado, e a Atividade, mediada pela linguagem, resultou, na maior parte das propostas, na transformação do MD em diversos âmbitos.

Cabe destacar uma mudança de perspectiva que vislumbramos em uma das respostas de A5 aos questionários on-line. No excerto 6, apresentamos as respostas de A5 à pergunta "qual é o papel social do professor de inglês?".

Excerto 6: Respostas de A5 aos questionários on-line (respostas obtidas no início e no final do curso, respectivamente).

A5, Resposta 1. O professor de inglês tem o dever de levar aos alunos os mesmos debates e questões promovidas por qualquer outro professor de outra disciplina. Tentando envolver essas questões sociais, com seus objeto de ensino [sic]. É importante que o professor não só repasse conhecimento, mas tenha uma relação com os alunos que permita o desenvolvimento de um ser crítico. O professor de inglês nesse contexto, pode trazer aos alunos outras perspectivas de outros lugares do mundo, por exemplo, já que o inglês é uma língua estrangeira.

A5, Resposta 2. O professor de inglês, assim como qualquer outro professor, deve não só ensinar os conteúdos da sua disciplina, mas também relacioná-los com questões sociais, incitar nos alunos um pensamento crítico, promover momentos em que se haja questionamento e aceitação do ponto de vista do outro. 
No excerto 6, vemos que, embora a primeira resposta de A5 já marcasse a importância das questões sociais e do pensamento crítico na relação do professor com os alunos, a segunda resposta traz esses elementos de forma mais aberta ao diálogo. Se na primeira resposta o professor aparece como aquele que traz a diversidade de perspectivas para a sala de aula, na segunda resposta ele aparece como aquele que promove "questionamento e aceitação do ponto de vista do outro". Essa mudança parece-nos significativa para futuras implicações metodológicas dessa professora em formação.

Acreditamos que o exemplo que demonstramos no excerto 6 nos mostra que um enfoque contínuo na abertura de espaços dialógicos nos contextos de formação inicial, em que se dê voz e espaço para ouvir os alunos/professores, pode trazer contribuições para a formação desses sujeitos.

\section{Considerações finais}

Neste artigo observamos diversas marcas da colaboração no diálogo e o impacto das sugestões na transformação dos materiais produzidos pelos professores em formação. Em nossa análise percebemos que as sugestões feitas pelos sujeitos da pesquisa durante os diálogos foram um fator crucial para as transformações dos MD. Analisamos também as valorações dos sujeitos acerca da experiência e percebemos como a abertura de espaços para o diálogo foi avaliada como positiva pelos participantes da pesquisa.

\section{Referências}

ANDRADE, Maria L. C. V. O. A repetição como elemento condutor do tópico discursivo. Filologia e Linguística Portuguesa, São Paulo, n. 2, p. 179-204, 1998. Disponível em: https://bit.ly/2LSoqd5 . Acesso em: 23 maio 2020 .

ARAÚJO, Philipe P. B. O diálogo crítico colaborativo na formação de professores: ambivalências na representação da identidade docente na 
O efeito de sugestões críticas...

produção de materiais didáticos. 2018. Dissertação (Mestrado em Linguagem e Ensino) - Unidade Acadêmica de Letras, Universidade Federal de Campina Grande, Campina Grande, 2018. Disponível em: https://bit.ly/36qjCW3. Acesso em: 23 maio 2020.

BAUMAN, Zygmunt. Modernidade líquida. Rio de Janeiro: Zahar, 2001.

BAUMAN, Zygmunt. Entrevista com Zygmunt Bauman. Tempo Social, São Paulo, v. 16, n. 1, p. 301-325, 2004. Disponível em: https://bit.ly/3d9hTXm . Acesso em: 23 maio 2020.

BAUMAN, Zygmunt. Sobre educação e juventude. Rio de Janeiro: Zahar, 2013.

ENGESTRÖM, Yrjö. Expansive learning at work: toward an activity theoretical reconceptualization. Journal of Education and Work, v. 14, n. 1, p. 133-156, 2001. Disponível em: http://bit.ly/2odRoXn . Acesso em: 19 out. 2019.

GIL, Antônio C. Como elaborar projetos de pesquisa. 4. ed. São Paulo: Atlas, 2007.

HASHIM, Nor H.; JONES, M. L. Activity theory: a framework for qualitative analysis. In: 4th International qualitative research convention. Anais... Malaysia: PJ Hilton, 2007. Disponível em: https://bit.ly/3eaqjht . Acesso em: 23 maio 2020.

JOHN-STEINER, Vera. Creative collaboration. Oxford: University Press, 2000.

KALANTZIS, Mary; COPE, Bill. Learning by design. Melbourne: VSIC, Common Ground Publishing Pty Ltd., 2005.

KOCH, Ingedore G. V. A inter-ação pela linguagem. 5. ed. São Paulo: Contexto, 2000. 
LIBERALI, Fernanda C. Argumentação em contexto escolar. Campinas: Pontes, 2013.

LIBERALI, Fernanda C. Formação crítica de educadores: questões fundamentais. Campinas: Pontes Editores, 2012.

LIPOVETSKY, Gilles. A era do vazio. Barueri: Manole, 2005.

MAGALHÃES, Maria C. C. Critical collaborative research: focus on the meaning of collaboration and on mediational tools. Revista Brasileira de Linguística Aplicada, Belo Horizonte, v. 10, n. 3, p. 773-797, 2010.

Disponível em: https://bit.ly/2TuCrSI . Acesso em: 23 maio 2020.

MAGALHÃES, Maria C. C. Escolhas teórico-metodológicas em pesquisas com formação de professores: as relações colaborativo-críticas na constituição de educadores. In: MATEUS, Elaine; OLIVEIRA, Nilceia B. Estudos críticos da linguagem e formação de professores/as de línguas: contribuições teórico-metodológicas. Campinas: Pontes Editores, 2014. p. $17-48$.

MARTINS, Onilza B.; MOSER, Alvino. Conceito de mediação em Vygotsky, Leontiev e Wertsch. Revista Intersaberes, v. 7, n. 13, p. 8-28, jan./jun. 2012. Disponível em: https://bit.ly/3bYZzik . Acesso em: 23 maio 2020.

MOLON, Susana I. Subjetividade e constituição do sujeito em Vygotsky. 5. ed. Petrópolis: Vozes, 2015.

NININ, Maria O. G. Da pergunta como ato monológico avaliativo à pergunta como espaço para a expansão dialógica: uma investigação à luz da Linguística Aplicada sobre modos de perguntar. São Carlos: Pedro \& João Editores, 2013.

PERELMAN, Chaïm; TYTECA, Lucie. Tratado da argumentação: a nova retórica. São Paulo: Martins Fontes, 1996. 
O efeito de sugestões críticas...

REGO, Teresa C. Vygotsky: uma perspectiva histórico-cultural da educação. 25. ed. Petrópolis: Vozes, 2014.

SILVA, Daniela M. V. Aprendizagem mediada por signos e a construção de conceitos em uma perspectiva vigotskiana. Educação Pública, v. 17, ed. 8, s. p., 2017. Disponível em: https://bit.ly/2ysvH09 . Acesso em: 23 maio 2020 .

SILVA, Marcos A.; CHAVES, Anna L. A. Os elementos modalizadores e a construção da argumentação no interior do gênero resumo acadêmico. In: SIMPÓSIO NACIONAL DE LINGUAGENS E GÊNEROS TEXTUAIS, 4., 2017, Campina Grande. Anais [...]. Campina Grande: Ed. Realize, 2017, s. p. Disponível em: https://bit.ly/2A10PnV . Acesso em: 23 maio 2020.

VYGOTSKY, Lev S. A formação social da mente. São Paulo: Martins Fontes, 1991.

Recebido em:06/12/2019

Aceito em: 08/05/2020

Title: The effect of critical suggestions for the redesign of pre-service teachers' didactic materials 